\title{
Analysis on the Relationship between Audit Fee Management and Audit Quality in China
}

\author{
Jiabing $\mathrm{Xu}$ \\ North China Electric Power University in Beijing \\ 18810795207@163.com
}

Keywords: Audit fee management; Audit quality; Feasible suggestions

\begin{abstract}
Audit fee management is an important factor that affects audit quality. It is a systematic project to standardize audit market management, promote the rationalization of audit fee management and improve audit quality. Audit quality is an important standard to measure audit service. Demanders are difficult to accurately evaluate the quality of audit services. They often judge their willingness to pay for the audit by judging their current service quality, such as auditing the company's reputation and the number of litigation involved. Therefore, studying the impact of audit fee management on audit quality has become an urgent topic. Based on the basic and unfavorable factors affecting audit fee management, this paper analyzes the current status of audit fee management and puts forward some feasible suggestions to improve the audit quality.
\end{abstract}

\section{Introduction}

As a link between accounting firm and audited entity, audit fee management is not only related to the reputation of CPA industry and its future development, but also related to the interests of investors in the audited entity, so as to affect the audit quality. With the further development of market economy in our country, the audit fee management system has been gradually established. However, due to imperfect regulatory mechanism and immature market development, the standardization of audit fee management is still a relatively tricky issue in the audit market.

\section{The Relationship between Audit Fee Management and Audit Quality}

Audit fee refers to the price reached by audit providers on both sides of audit services, which is the economic connection between customers and accounting firms and CPA. As an independent accounting and self-financing unit, the accounting firm has to consider the cost and effectiveness of the business. Audit fee management is the key factor that determines the cost and profit of the firm. It is also a prominent issue in the firm's business competition.

Audit fee management and audit quality influence each other. In general, the better audits provided by the firm and the CPA are, the higher the audit fees are, but excessive audit management fee may also allow the principal to select smaller firms and thereby reduce the audit quality.

Audit fee seriously affects the audit quality. Low management fee is not conducive to attract and gather high-quality audit talent, not enough to support the staff to invest in professional knowledge and skills training, and makes the CPA have no professional competency to detect errors and disadvantages. Low fees can only be matched with lower service costs, so that CPA may reduce audit procedures, fail to maintain professional ethics, and reduce audit quality. On the contrary, the more perfect the quality control system of the firm, the higher the quality of practice, the more the audit management cost is required.

From the perspective of "rational economic man", when the firm undertakes the audit business, only the higher audit management fee can guarantee all the strength of the firm to perfect the quality control system so as to ensure that the firm has the ability to pay more audit costs to practice and ensure a high audit quality. Of course, if the audit management fee is too high, there may be "purchase audit opinion" behavior, resulting in the firm's extremely dependence on the audited entity. 


\section{The Current Situation of Audit Fee Management under the Market Environment of China}

The Unreasonable Model of Audit Entrustment. In theory, in the audit business commission model, certified public accountants accept the commission of the company's owners, and audit the company's operating conditions and financial position. However, due to the separation of powers and the existence of agency relationship, in fact, the audit principal becomes the management of the company, and the trilateral relationship has become a relationship between the two parties, resulting in limited bargaining power of the firm. If the management lacks integrity, the internal control is weak and the risk of material misstatement of the financial statements may be high. There are two situations when entrusting the audit business: One hand, for their own salary and the company's stock price, the office loses its independence by buying office at a high price and purchase standard audit opinion. The other hand is to make use of the shortcomings of small and medium-sized firms in the poor market competitiveness of customers. By changing accounting firms and taking advantage of the discount behavior of audit contracts, the audited units get both the desired audit opinion and the audit fee.

The Level of Domestic Audit Fee Management is Generally Low. First is the comparison of international and domestic environment. Due to the immature development of market economy in our country, the development level of enterprises varies greatly and the supervision system is imperfect. Compared with the average management level of audit fee abroad, the management level of audit fee in our country is relatively low. Second is the comparison of the "big four" and local firms. The "big four" maintains a high market share in our country. The audit management fee is much higher than that of local firms. In order to establish a good reputation image in the market, large-scale listed companies will not care about the cost and have a long history of good image. The "big four" is also more willing to accept the commission of such enterprises. The risk of material misstatement of small and medium-sized enterprises is relatively high. The "big four" is not willing to accept the entrustment. In order to increase the business volume, the small local firms attract customers by pushing down the management fee. Too low auditing charge management, coupled with incomplete quality control procedures in the firm, CPA is likely to reduce audit management costs by reducing the necessary audit procedures. Such a vicious cycle has created an unreasonable market phenomenon that foreign investors maintain high fees for auditing and local agencies depress fees.

Imperfect Supervision Mechanism. First, audit fee management disclosure system is not perfect. Although the CSRC has specifically stipulated the contents and forms of remuneration paid to certified public accountants by listed companies, the quality of disclosure is not satisfactory due to the actual implementation situation. The information is complicated and confused, and the comparability of the data is not strong. Second, punishment is not enough.

Insufficient Effective Demand. First, in terms of audit service needs: there are 3000 listed companies and 8000 accounting firms. This is a typical buyer's market which lacks of market demand. Second, in the aspect of auditing users of the products: as an important part of the final user of audit products, corporate investors often have speculative psychology and lack high quality audit services.

The Internal Audit Management Mechanism of the Audited Unit is not Perfect. Although domestic listed companies set up audit committees in accordance with the regulations, due to the unreasonable establishment of personnel and the imperfect internal control of enterprises themselves, the risks of material misstatement by themselves are enlarged. This makes the external audit agencies and personnel need to take more complex and rigorous audit procedures, and audit fee management also increases at the same time.

Lacking of Clear Standards for the Audit Fee Management. In foreign countries, the audit fee management takes working hours as the standard, and the audit fee has a more objective evaluation basis. In our country, the charge of audit is the model of government pricing, which is based on the price law of People's Republic of China and the measures for fee management of intermediary services. However, there are great differences in standard, large space and no compulsion, which further leads to the abnormal competition in China's audit market. 


\section{Perfecting the Audit Fee Management System and Improving the Audit Quality}

Strengthening the Construction of Large Audit Institutions. At present, there are more than 8,000 offices in our country. Generally speaking, there are problems such as low practicing level, difficulty in introduction of qualified personnel, poor risk resistance ability and uneven audit quality. Only by further expanding the scale of domestic firms, joining forces and taking the road of group development, can we cope with the increasingly powerful market demand for the quality of audit services.

To strengthen the construction of domestic firms on their own, it is necessary to improve the conditions for the establishment of offices and improve the procedures for registering firms and to encourage small and medium-sized firms to restructure to form large-scale firms by means of merger and reorganization.

Establishing a Unified Standard of Fee Management to Create a Fair Competition Environment. The collection of audit management fee should follow the principle of marketization. We can learn from international practice, according to the size of the company, sales income, financial status, internal control strength and the complexity of accounting industry to predict workload and different levels of audit staff, according to the different levels of charges, to determine the audit management fees. Specifically, we take the management cost as the starting point, find the law of the cost of the industry, and formulate the cost standard of the industry from the perspective of inputting fees and charges of human resources so as to standardize the price order and form an orderly competition. Charge management standards can set the upper and lower audit fees. The CPAs around the country follow the standard at the time of the audit, and charge within the upper and lower limits of the standard, so as to prevent the auditor from vicious competition.

Changing the Payment Mode of the Existing Audit Management Cost Through the Third Party Intervention. As our country does not have the conditions for the audit report users to pay for the audit and administration fees now, aiming at the phenomenon that the auditing client and the auditee are combined into one at the same time, an independent third party should be added between the firm and the audited entity institutions, that is the audit supervision center. It is a non-profit regulatory body and must be able to guarantee impartiality.

The establishment of the audit supervision center cuts off the negotiation of the economic interests between the two to prevent the purchase of audit opinion and establishes the audit entrustment relationship between "the enterprise (the entrusting party) - the audit supervision center - the accounting firm" and organizes the tendering and bidding work of audit business, changes the mode of audit payment and supervises the quality of audit.

The method of bidding is improved and the minimum price is formulated according to the actual situation. In the process of bidding, we should give full consideration to the firm's reputation, scale, quality of service and other factors, and give a comprehensive evaluation. At the same time, measures should be taken to improve the transparency of bidding work, standardize information disclosure, and strengthen social supervision.

Restricting the Diversity of Services that Are Incompatible with the Audit Business Properly. Under the current audit market management system, the competition of firms is more and more intense. In order to survive and develop, we must expand new business fields and provide management consulting services for enterprises. However, if the firm provides both the audit service and the management advisory service to the same listed company, it will seriously affect the independence of the audit.

Adopting the mode of "not forbidding non-audit business basically", the relationship between consulting business and audit business is clearly defined by the laws and regulations, and the CPA is required to separate the consulting service and audit service provided to the customer, that is the only one service, so as to formally and substantially improve the independence of the CPA.

Strengthening Supervision and Increasing the Penalties for Violations of Laws and Regulations of Accounting Firms. We should form a perfect legal responsibility on the CPA norms, increase the legal responsibility of CPA, and strengthen the liability. After the introduction of unified audit fee, government departments can monitor the illegal acts of the firm, and prohibit 
unfair low-cost competition. At the same time, government departments should impose greater penalties on ultra-low fee firms to ensure the smooth implementation of audit fee management standards.

In order to improve the long-term supervision of audit quality, it is necessary to vigorously promote the integrity of the system in the CPA industry, strengthen brand awareness and firm CPA construction, reputable firms can perform a high level of audit fee, and firms will guide the price competition into a higher level of audit quality competition. Supervision departments should often check the integrity of the entire industry, timely announce each credit level. The good development of CPA industry can be promoted through the mechanism of good faith system and economic benefit.

Strengthening the Information Disclosure System of Audit Fee Management and Enhancing the Transparency of Social Supervision. The disclosure of audit fee management information helps the public to supervise the firms, reduce the unfair behavior in the management of audit fee, and curb unfair competition by price. We should formulate laws and regulations to standardize the audit fees and related information disclosure, and stipulate that the enterprises need to disclose the contents to be comprehensive, objective, clear and true.

We disclose information through designated websites or newspapers, make it convenient for information users to access, and implement the confirmation system of information disclosure by firms. The CPA Association at all levels can establish a system of business fee declaration, and restrict and supervise all the professional CPA and firms to make the audit fees more transparent and standardized. As a supervision department, we need to identify problems in time, strengthen the inspection and supervision of information disclosure and audit fees, establish a social supervision mechanism for industrial integrity, and create a clean environment for CPA audit.

\section{Conclusions}

In a word, China has a large number of firms with small scale and little differences in audit services. Excessive and unordered competitions in the audit market are not conducive to the improvement of the audit quality and the existence and development of the accounting firms in the market competition. The audit quality plays an important role in the decision-making of the investors. The audit fee management is one of the important factors that affect the audit quality. Therefore, we should constantly improve the audit fee management system, in order to promote the improvement of audit quality and provide information users with real audit information.

\section{References}

[1] X.M.Zhang: Analysis of the Influence of Audit Fee Management on Audit Independence in China[J], Modern Science, 2006(06): 13- 14.(In Chinese)

[2] P.Zhou: Suggestions on Improving the Current Audit Fee Management System[J], Communication of Fiance and Accounting, 2005.(8):87.(In Chinese)

[3] T.G.Wang: The Current Situation of Audit Fee Management in China and Its Influence on the Quality of Audit [J], Management and Technology of SME( Periodical of the last ten-day of a month), 2009.02.(In Chinese) 